\title{
FENOMENOLOGIA, PSICANÁLISE E PROCESSO EDUCATIVO: ENTRE A RACIONALIDADE E A EMOÇÃO
}

\author{
Sueli Teresinha Abreu-Bernardes \\ Universidade de Uberaba - Uniube - Brasil \\ Osvaldo Freitas de Jesus \\ Universidade de Uberaba - Uniube - Brasil
}

\section{Resumo}

Em uma perspectiva interdisciplinar, este trabalho pretende fundamentar indagações sobre uma possível aproximação à fenomenologia, quando Bion propõe o estado mental sem memória e sem desejo, no sentido da disponibilidade do analista para viver a experiência emocional que se apresenta na relação analítica. Partindo de uma leitura hermenêutica dos conceitos de Husserl sobre a epoché fenomenológica e das ideias identificado no artigo "Notes on memory and desire" de Bion (1967), procurou-se compreender como o estado não confusional entre analista e analisando é preservado quando se usa o procedimento bioniano. Em fidelidade às reflexões que esses estudos provocaram, também são apresentadas as inferências realizadas para o processo educativo.

Palavras-chave - fenomenologia e psicanalise, processo educativo, interdisciplinaridade.

\section{Introdução}

A fenomenologia surgiu na onda de esforços das ciências humanas, à procura de rigor conceitual e teórico, tal como as ciências empíricas haviam feito e, sobretudo, a matemática sempre fez. Nesse movimento epistemológico, Edmund Husserl (1949, 1992) não mediu esforços para faxinar a consciência, à procura da eidos (ideia) pura, associada à intencionalidade, bem como de suas articulações noéticas, utilizando-se da epoché, como estratégia de acesso aos fenômenos ideacionais.

Como um matemático, Husserl propôs no final de sua carreira, nas famosas Conferências de Paris (1992), o conceito de Lebenswelt que abriu portas para a expressão dos sentimentos e afetos, componentes esquecidos na fenomenologia pura e diminuídos na cultura racional e iluminista.

A eidos pura, ou a pérola branca pela qual procura Husserl, junto ao pathós puro (emoção), combinam-se, para formar a estética da obra de arte, pois a racionalidade e a emocionalidade formam a expressão completa dessa criatura que é Dasein, ou o Ser-aí, o 
portador do passaporte que encaminha as coisas do mundo do silêncio para a linguagem, ou a casa do Ser.

Mas foi em Jean-Paul Sartre (1943) que a relação interpessoal ganhou categorias conceituais ricas e capazes de expressar o fato de que o Para-si, a consciência, ao formar-se com o Em-si dos objetos e fatos do mundo, nadifica-o, pois o Ser do Para-si é apenas uma representação da mente.

Os Para-sis são iguais em sua constituição, inclusive não terminam sua Para-sidade, enquanto se relacionam. A intersubjetividade é de mão dupla e permite um intercâmbio continuado de experiências pessoais entre Para-sis. Entretanto, uma relação especial acontece entre o analista e seu paciente, à medida que o primeiro se inclui na epoché do outro, para que aquele possa harmonizar sua racionalidade e suas emoções, entrelaçadas pelas experiências conflituosas da vida. Esse método epoqueizado permite ao analista (o Para-si-analista) encorajar o (Para-si-paciente) à introspecção e à retomada de seus embaraços racionalemotivos e a reconquistar a convivência harmônica entre a racionalidade e a emocionalidade.

De reflexões como essas emerge, no presente texto, a proposta interdisciplinar de dois educadores para entrelaçar conceitos da fenomenologia husserliana e de um procedimento psicanalítico, os quais contribuem para pensar o processo educativo.

Para alcançar esse propósito, realizou-se uma leitura hermenêutica da bibliografia selecionada, com aporte em Ricoeur (2008). Segundo a perspectiva teórica desse filósofo, o caráter formativo da leitura efetiva-se sempre no diálogo do sentido do texto com o sentido do mundo, em um ato realizado além do mundo textual. A leitura da palavra não se limita, pois, a uma decodificação mecânica de sons e significados.

Para Ricoeur (2008), todo texto alude a um mundo com o qual se dialoga por meio de uma interpretação que não tem em vista apenas a compreensão da obra, mas o entendimento de si diante da obra. No processo de leitura, o afastamento que a escrita gera faz com que se rejeite a procura pelos intentos do autor, em benefício do sentido que a obra sugere e/ou permite. Contudo, para usufruir esse caminho que a literatura oferece, é necessário expor a subjetividade à obra, despir-se das adivinhações e pré-definiçõoes e lançar-se ao mundo que ela propõe.

Acompanhando, ainda, o pensamento desse fenomenólogo, o discurso como escrita torna-se autônomo em relação ao autor. Poder-se-ia dizer que na leitura hermenêutica proposta neste texto, como os autores já não podem mais responder às perguntas, resta aos leitores tão somente ler e interpretar seus textos (SALLES, 2009). 
Desse modo, apropria-se do sentido de mundo que as obras oferecem, sendo que, para Ricoeur (2008) esse sentido não se localiza atrás do texto, mas diante dele, como aquilo que a obra revela, descobre, mostra.

\section{A proposta de um analista}

Inicialmente convida-se o leitor para ouvir a voz de um poeta, pois "na ordem da filosofia só se persuade bem sugerindo devaneios fundamentais, restituindo aos pensamentos sua avenida de sonho" (BACHELARD, 1942, p.5). Os artistas da palavra nada explicam, apenas mostram o todo que não se alcança apenas com a filosofia ou com a ciência (ABREUBERNARDES, 2011), como se lê nos versos de Impaciência:

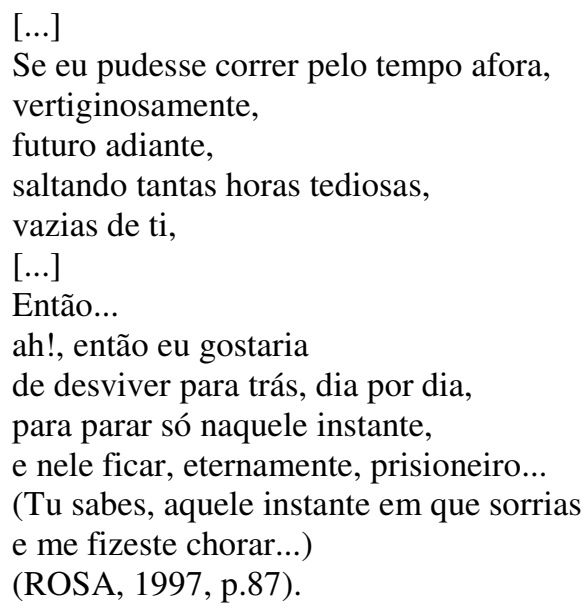

Desperta a atenção, nesse poema, o modo como o poeta vai discorrendo sobre o seu desejo, até que, ante a possibilidade de não satisfazê-lo - pois o desejo, de algum modo, nutre-se com sua própria fome e amplia-se com a sua satisfação - recorre então à memória. É interessante notar não apenas que o poema sugere desejo e memória, mas que um e outra levam o poeta não a viver o agora de sua realidade e, sim, o que ocorrerá ou o que já aconteceu. A apreensão do desconhecido no instante pode ficar opacificado, e mesmo impedido, quando se impregna das percepções sensoriais de história e de futuro. Bion, sobre esta possibilidade, irá dizer que

Memórias e desejos [...] são duas facetas da mesma coisa: ambos se compõem de elementos baseados em impressões dos sentidos; ambos implicam a ausência de imediata satisfação sensorial; [...] Se a mente estiver preocupada com elementos perceptíveis aos sentidos, estará muito menos capaz de perceber elementos que não podem ser sentidos (BION, 1984, p.41). 
A recomendação de que, em toda sessão analítica, o analista deve trabalhar evitando "memória, desejo e compreensão" é uma das contribuições mais originais que Bion fez à teoria psicanalítica. Memórias e desejos interferem, no analista, com o que poderia ouvir daquilo que o paciente, ao dizer, está criando dentro dele. Para Bion, se o analista ainda não se despojou, deliberadamente, de memória e desejo, o paciente poderá sentir isso e ser dominado pelo sentimento de que está possuído e contido no estado mental do analista, isto é, no estado representado pelo termo desejo, dificultando o desenvolvimento da análise. $\mathrm{O}$ analista procura alguma coisa que difere do normalmente conhecido como realidade, seu propósito é conseguir contato com a realidade psíquica. Como ele alcança esse propósito? É a primeira indagação que vem à mente.

$\mathrm{Na}$ busca para apreender o sentido da recomendação de que em toda sessão analítica o analista deve trabalhar evitando memória, desejo e compreensão, se o encontro com a poesia é o ponto de partida, propõe-se, essencialmente, a análise das articulações dos conceitos fundamentais existentes no procedimento descrito, que ora é chamada de uma possível aproximação à fenomenologia em Bion, por meio de uma leitura hermenêutica.

Bion não foi um filósofo; porém, sua obra, ainda que possa ser considerada uma ampliação e refinamento da observação clínica e teoria de Melanie Klein, gira em torno de uma atividade intelectual que é essencialmente filosófica, por isso são apresentadas questões de fundamento filosófico aos seus escritos.

Da extensa obra de Bion, este estudo abrange, sobretudo, o artigo "Notes on Memory and Desire” (1967) e recorre, em alguns momentos, aos capítulos três e quatro do Attention and Interpretation (1993) e a alguns recortes de Learning from experience (1991), nos quais ele aborda o tema escolhido. Ao procurar compreender como os diferentes conceitos se interagem, busca-se identificar como Bion resolve a questão da não identificação entre analista e analisando, ao propor a atitude sem memória e sem desejo. Entende-se que, suspendendo história e futuro, há uma aproximação entre os protagonistas da sessão analítica; então, atuando sem memória e sem desejo, o analista alcança, por uma intuição, o sentido da realidade psíquica do analisando em uma relação em que cada um preserva a sua identidade. Isso se faz à semelhança da epoché fenomenológica de Husserl, a qual possibilita a aproximação entre sujeito e objeto, mas não a identificação, pois há uma intencionalidade que os mediatiza.

É sabido que outras análises que aproximam o procedimento bioniano de um pensamento fenomenológico têm sido feitas com o rigor da formação que especialistas da psicanálise possuem. As diferentes reflexões sobre o sentido de memória em Bion, ora 
aproximando Bion e Mestre Eckhart (MARONI, 2005), ora Bion e o artista plástico Leonilson (ASSIS, 2011) animam a proposta de mais uma, falando a partir da filosofia e da educação.

Nem Husserl, nem Bion elaboraram estudos específicos ou teorias sobre educação. No entanto, durante as reflexões na criação deste artigo, questões emergiam do pensar o sentido de: o que a fenomenologia traz como contribuição para os educadores? Como o diálogo com Bion pode ser fecundo e proveitoso para quem o faz na porta da escola? E, ainda, sem o procedimento sem memória e sem desejo pode aplicar-se ao processo educativo? São perguntas que apontam caminhos e que se pretende fundamentar.

\section{Psicanálise e Filosofia: sintagma ou sistema?}

É notória, na literatura psicanalítica, a predominância de um rico mundo teórico de modelos e técnicas. A leitura de publicações especializadas, os trabalhos apresentados em congressos e reuniões científicas mostram uma riqueza de produção, aproximando-se do pensamento que calcula, isto é, que amplia o saber a partir de dados e fatos, mas não pensa o sentido de si mesmo ou de qualquer coisa. No cenário do cálculo, as teorias psicanalíticas endossam o vigor da modernidade. Mas existe também um mundo terapêutico de tratamento e clínica que inclui settings, interpretações, transferências, atuações, reações, progressos, resistências, melhoras, regressões. E, nesse mundo, divergências de interpretação clínica e de endereço teórico tendem a um impasse epistêmico. A falta de pensar o sentido poderia contribuir para que o analista sinta isso? Só o pensamento irrequieto que calcula, que produz teorias, não é suficiente para o inesperado na sessão analítica.

Segundo Dartigues (1972), ao descobrir que a neurose não é um sintoma, Freud transcende o universo dos fatos e cria para o discurso da psicanálise um novo universo, o universo do sentido. Ao afirmar que o ato humano tem sentido, ele contribui para desenvolver um pensamento filosófico.

Os analistas que, na intenção de se aprofundarem na psicanálise, buscam um desenvolvimento de habilidade técnica e um maior conhecimento de suas teorias, produzem o pensamento do cálculo e unidimensionam o trabalho psicanalítico. O universo do sentido é onde se insere a interpretação clínica, pois esta não é uma simples percepção de fatos, mas um processo de escutar e elaborar evidências de identidade. Para tal, exige uma atitude de atenção flutuante, segundo Freud, ou sem memória e sem desejo, segundo Bion. Em oposição a um fato, a interpretação nunca poderá ser demonstrada nos moldes do discurso axiomático- 
dedutivo, nem submetida a testes nos moldes do discurso empírico-dedutivo. Sua legitimação está no campo da intersubjetividade, e não da objetividade, e nos limites da identificação.

O pensamento que calcula e o pensamento que pensa o sentido são dois universos com epistemologia própria de discurso. Contudo, o pensar não é seguir só uma dimensão, mas compor oposições, pensar a pertinência de cálculo e sentido; por isso, na psicanálise não se podem salientar só teorias e técnicas, como também não se deve enfatizar apenas o campo clínico.

No texto Notes em análise, infere-se que Bion estimula à composição do pensamento, a pensar a pertinência de cálculo e a encontrar a exuberância do sentido na própria limitação do pensamento. Esse parece ser o seu apelo. A busca do pensar o sentido não vem como substitutivo ao cálculo, mas vem da espera de um sentido não esperado. Esses dois universos remetem ao encontro da filosofia e da psicanálise, segundo o pensamento de Emmanuel Carneiro Leão (1977). Porém, esse e não é apenas sintagma, mas um desafio que provoca a integração e a reciprocidade entre elas. É um sistema. A leitura de um texto psicanalítico a partir de um pensamento filosófico não poderá, pois, ser estranha e incoerente à própria natureza dos dois modos de pensar.

Bion (1995) fala sobre a dificuldade em apreender a intenção em um de seus Seminarios Clinicos y quatro textos. Em fragmentos de uma supervisão, observa-se que a compreensão de outrem (da paciente pelo analista) e a própria compreensão de si (da analisanda) vão de encontro a uma opacidade difícil de reduzir, e que o sentido aparente de um comportamento dissimula um sentido mais profundo (como é o caso do modo de se vestir da paciente e a sua intenção ao fazê-lo, como é relatado).

A razão desse tipo de dificuldade pode estar no fato de que a consciência não se contém toda inteira dentro do instante em que manifesta sua intenção; ela lança raízes fora do momento em que a consciência a formula. "Há uma dimensão da consciência que por mais que avancemos, sempre haverá algo mais além [...] é como o horizonte à frente de nós... a ele nunca chegamos... [...]" (JUNQUEIRA-MATTOS, 1997, p.6).

Assim como o pensador de Morávia busca pensar a realidade de modo rigoroso e para isso propõe um método, o fenomenológico, Bion, ao procurar conhecer a realidade psíquica, propõe um procedimento e uma disciplina cujas regras de agir sugerem constituir uma atitude que se aproxima da fenomenológica. Além dessa proposta de rigor metodológico, nota-se uma congruência entre a fenomenologia e a teoria psicanalítica bioniana no propósito de perceber o ato humano a partir do interior, do ponto de vista da intenção que anima o sujeito. 
Mas, como a possível atitude fenomenológica de Bion se realiza e se organiza na sua teoria? Que relação analista-analisando dela decorre?

\title{
O sentido de sem memória e sem desejo
}

As duas questões - memória e desejo - foram associadas por Bion ao propor um procedimento psicanalítico e comunicadas principalmente em um artigo e em um livro, já citados neste artigo. Neles, esclarece o seu sentido e orienta, metodologicamente, o seu uso: o analista deve trabalhar sem memória e sem desejo. Do texto Notes, é transcrita esta primeira afirmação:

\begin{abstract}
A memória é sempre equívoca como registro dos fatos, já que está distorcida pela influência de forças inconscientes. Os desejos interferem no funcionamento do juízo, devido à ausência da mente quando a observação resulta essencial. Os desejos distorcem o juízo porque selecionam e suprimem o material por julgar. A Memória e o Desejo exercitam e intensificam aqueles aspectos da mente que derivam da experiência sensorial. Promovem assim uma capacidade derivada das impressões sensoriais e destinadas a servi-las. Tem a ver, respectivamente, com as impressões sensoriais do que se supõe que tenha ocorrido e as impressões sensoriais do que, todavia, não sucedeu (BION, 1967, p.272).
\end{abstract}

Segundo o sentido que o analista lhe dá, a memória é uma capacidade psicanalítica derivada de impressões dos sentidos e destinada a servi-las. O analista ficaria, desse modo, preso a dados sensoriais e não teria acesso à realidade psíquica? Essa questão decorre da afirmação em Notes (BION, 1967, p.272): "ansiedade não tem forma, odor, gosto, porém, todos os analistas conhecem a depressão, a ansiedade, o temor e outros aspectos da realidade psíquica”. Para ele, sentimentos, paixões não são observáveis sensorialmente. A realidade psíquica apresenta realizações destituídas de componentes da sensibilidade. Além disso, impressões sensoriais constituem obstáculo para a intuição que o analista tem da realidade psíquica; o que se sabe sensorialmente carece de importância. "Se é conhecido, é irrelevante”, afirma em sequência.

Ao expor os limites que se impõem ao analista que trabalha com memória e com desejo, Bion (1992, p. 108) diz: "quanto mais uma pessoa ficar ocupada com aquilo que ela quer que aconteça e com aquilo que aconteceu, ou com aquilo que ela sabe sobre o paciente ou sobre psicanálise, menos espaço sobra para a incerteza”. Segundo ele,

Heisenberg formulou seu Princípio de Incerteza com clareza, mas em sua busca da verdade descobriu não apenas o Princípio da Incerteza como também a possibilidade de que exista uma coisa que é a incerteza. A incerteza não tem cor, não tem cheiro, 
não é palpável, mas ela existe. [...] O Princípio da Incerteza de Heisenberg é uma etapa importante na jornada, é deplorável que qualquer parte da humanidade possa estar certa. Se existe algo que é certo, é que a certeza é errada (BION, 1992, p. 108).

Ou seja, mesmo que apegado ao sensorial, se pudesse atingir a realidade psíquica ainda haveria a limitação de se ater à memória, ao desejo e não ficar disponível à incerteza, pois como também escreve em Notes (BION, 1967, p. 272): “o único importante em qualquer sessão é o desconhecido e nada deve impedir-nos de intuí-lo".

Mas o que o analista fará com os dados sensoriais armazenados na memória?

Bion (1967, p. 273) afirma que o analista deve procurar, vigilantemente, evitar a memória, e ainda: "o analista deve buscar um estado mental de tal modo que em cada sessão sinta como se não tivesse visto o paciente antes". Se tal fato ocorrer, ele não estará deixando sua história, seu passado, suas lembranças entre parênteses? O que fará não é suspender o conhecimento, as teorias, as hipóteses a respeito do analisando? Em sua obra Attention and Interpretation (1984, p. 46) ele fala em “suspensão de memória e desejo".

\section{Ideias fenomenológicas}

Como se aproximam essa suspenção de memória e desejo e a redução fenomenológica? Em Ideas (1949, p. 74), Husserl escreve sobre um método de colocar as teorias entre parênteses.

a experiência tomada plenamente 'livre de teorias', tal como ocorre na experiência real, $[\ldots]$ não vale para nós agora nada; sem colocá-lo à prova. Porém também sem discuti-lo, deve permanecer entre parênteses. De igual modo devem sucumbir ao mesmo destino todas as teorias e ciências que se referem a este mundo [...].

Conhecer esse mundo de modo mais completo, mais seguro, mais perfeitamente do que pode fazê-lo a experiência ingênua é o que nosso filósofo propõe. E esse instrumento metódico de colocar entre parênteses não só os dados da percepção sensível, mas as teorias e as ciências, não significa negar este mundo, nem duvidar de sua existência, "senão que pratico a epoqué fenomenológica que me encerra completamente todo juízo sobre existências no espaço e no tempo" (HUSSERL, 1949, p. 73).

Sobre esse tema, expressa em Conferências de Paris:

Devo [...] abster-me das minhas outras opiniões, juízos, das minhas tomadas de posição valorativas na referência ao mundo, enquanto pressupõem o ser do mundo, e também para eles o abster-me não significa o seu desaparecimento enquanto simples fenômenos. Por conseguinte, esta inibição universal de todas as tomadas de posição 
face ao mundo objetivo, à qual damos o nome de epoché fenomenológica, torna-se justamente o meio metódico pelo qual me apreendo puramente como aquele eu e aquela vida da consciência na qual e para a qual todo o mundo objetivo é para mim, e é tal como para mim é (HUSSERL, 1992, p.15).

A epoché fenomenológica, se por vezes relembra a dúvida metódica cartesiana, não tem o mesmo sentido. O caráter metódico da dúvida husserliana está apenas em ser um critério a indicar que não se alcançou, ainda, a evidência apodítica. O mundo será visto apenas sob o aspecto de como se apresenta na consciência, reduzido à consciência.

Mas, por que, pode-se indagar ainda, a aproximação à epoché fenomenológica?

Não aceitando qualquer evidência, mas procurando as que se fundamentam na ausência total da dúvida, Husserl recuará até a imanência. Ao por entre parênteses tudo o que é exterior, circunstância em que em lugar do mundo em si emerge o mundo consciente, está explicitando a epoché no primeiro grau. Posteriormente o filósofo em questão discorrerá também sobre a epoché em um nível mais alto que leva à inibição de todo o interesse existencial. Nesse grau coloca-se entre parênteses não apenas o corpo como realidade existencial concreta que pensa, quer, sente, mas o eu na sua realidade total.

Voltando agora a Bion. O despojamento de memória e desejo, a mente despreocupada com elementos perceptíveis aos sentidos, o estado mental não possuído pela história ou pelo futuro não representariam analogamente o eu puro, o eu transcendental? Se se considera análogo o ser que há um tempo coincide e se diferencia em seu ser, é possível fazer essa relação para aclarar o conceito bioniano.

Bion usa um raciocínio fenomenológico, mas segue um percurso próprio. O que ele almeja é que o analista alcance um estado mental de tal índole que suas interpretações não derivem de percepções sensoriais, ou de teorias generalizadas e imperfeitamente recordadas. Elas devem estar suspensas. $\mathrm{O}$ analista deve deixar a mente aberta, sem influências anteriores, para buscar aproximar-se da verdade, da realidade última, que nunca é conhecida totalmente.

Mais uma vez, analogamente, pensa-se plausível esse procedimento de ir-à-coisamesma, ao sentido do mundo adquirido primeiro de mim e em mim, à busca de uma evidência imediata, numa ausência radical de pressupostos. Ao desconectar o mundo e o juízo sobre ele, ao suspendê-lo, o que não significa negá-lo, ou duvidar de sua existência, o que permanecerá para Husserl? O eidos que aparecerá como uma nova região de ser.

Eidos não tem aqui o sentido de Platão, como sendo ideias que se situam num mundo inteligível do qual o mundo sensível seria uma imitação. Mas as essências, no sentido fenomenológico, residem na consciência, já que é como vivências de consciência que elas se dão a nós. Mas se elas (as essências) estão na consciência, como não reduzi-las a fenômenos 
psíquicos? É aqui que a fenomenologia insere o conceito de intencionalidade. Todo o esforço fenomenológico de desocultamento da verdade, do que é essencial ao fenômeno, em síntese, a epoché fenomenológica, aproxima sujeito e objeto. O entre parênteses permite a intuição eidética, da essência, do sentido. Mas na fenomenologia essa aproximação não significa identificação. Sujeito e objeto não se confundem, porque a epoché se faz a partir de uma consciência intencional.

A concepção de intencionalidade assumida neste artigo é a que Husserl apresenta nas Conferências (1992, p. 21): "a propriedade fundamental dos modos de consciência que o eu vive como tal, é a chamada intencionalidade, é sempre ter consciência de alguma coisa." Ou, ainda, toda consciência é "consciência de". Por meio da intencionalidade Husserl está afirmando que a consciência é ao mesmo tempo consciência e mundo. A consciência não é manifestação só da consciência, mas da consciência e mundo. A relação noesis (sujeito) e noema (objeto) é mediatizada pela intencionalidade. A fenomenologia abrange o sujeito, a consciência e o mundo.

O princípio da intencionalidade expressa um sentido de consciência em que ela é sempre consciência de alguma coisa, ela só é consciência estando dirigida para um objeto. Por sua vez, o objeto só pode ser definido em sua relação com a consciência, ele é sempre objetopara-um-sujeito. Isso significa que o objeto não está contido na consciência como se estivesse dentro de um recipiente, mas que só tem sentido de objeto para uma consciência. Se o objeto é sempre objeto-para-uma-consciência, parte-se da coisa-mesma, isto é, do objeto-enquantopercebido. Essa correlação intencional consciência-objeto explica a não identidade.

Mas, se para Bion o analista volta-se para si mesmo ao experimentar emocionalmente a vivência emocional do paciente e, assim, aproxima-se de sua realidade psíquica, como preservar a identidade de sujeito (analista) e sujeito (analisando)?

No próprio artigo Notes (1967, p. 272), é possível encontrar a resposta quando ele afirma que o analista deve "disciplinar seus pensamentos, realizando uma análise pessoal tão completa quanto seja possível”. Nela o analista protege-se do estado confusional possível de existir no processo analítico, quando a vivência da experiência emocional, a identificação com a realidade psíquica do analisando pode gerar uma fusão. Para vivenciar a experiência emocional e interpretar, sem fundir-se, é preciso que o analista esteja com a mente livre para enfrentar a turbulência (expressão de Bion), ou pronto a alcançar a disposição de espírito em que estará receptivo a $\mathrm{O}$ (realidade ou verdade última) da experiência analítica. A análise pessoal e a re-análise dão um protetor ao analista, para que o mesmo não fusione os conflitos, resistências e desprazer do paciente com os seus próprios. 
A esse respeito, Bion escreve:

é para evitar a distorção advinda dos efeitos da história de cada um que se supõe que os analistas sejam analisados. Na prática, isto significa que 'conscientemente' a pessoa tenta excluir suas próprias memórias, portanto livrar a si mesma da memória; pela mesma razão a pessoa precisa 'conscientemente' excluir desejos. Quando não fomos analisados, ou quando estamos cansados, aparece o perigo da introdução de memória e desejos (BION, 1992, p. 108).

É na análise pessoal que o analista irá aprender a discriminar a realidade intrapsíquica da realidade externa e estruturar seu núcleo neurótico que lhe possibilitará, discriminando as necessidades e o desamparo do paciente, não se confundir com o mesmo.

Quando se afirma neste mesmo texto ser a intuição um conceito fundamental, é baseado no fato de que todo o procedimento sem memória e sem desejo visa dar condições ao analista de intuir além do que está explícito. A suspensão dos objetos dos sentidos permitirá perceber, na realidade psíquica, todos os equivalentes de todos os sentidos. Se a experiência mental é diferente, o aparelho para intuí-la não poderá identificar-se com as impressões sensoriais comuns.

Outro aspecto merece ser ressaltado. Em Notes (1967, p. 272), Bion diz: "A observação psicanalítica não se ocupa do que ocorreu nem do que ocorrerá, mas do que está sucedendo". Aqui existe uma noção de tempo lembrada por um analista bioniano: "a sessão analítica, como tudo mais, só acontece no presente. Assim quando um analisando se refere ao passado, que já não existe, ou a um futuro, que ainda não existe, o que está sentindo, está sentindo no exato instante" (JUNQUEIRA-MATTOS, 1997, p.15).

Nesse sentido, se toda sessão analítica ocorre no presente e se esse é fugaz e efêmero, é no uso da memória, como um mecanismo de defesa, que liga ao passado, e do desejo que une ao futuro, que haverá a ilusão da continuidade das experiências no tempo (JUNQUEIRAMATTOS, 1997, p. 9).

A noção de tempo é fundamental para a análise do procedimento bioniano, apesar de ligeiramente abordada em Notes, ao dizer que, se voltando para o instante, o analista estará suspendendo memória e desejo e se aproximando da realidade última.

Esse conceito de realidade última associa-se ao de desconhecido. Por mais completa que seja uma análise, em qualquer um de seus pontos a proporção entre o conhecido e o desconhecido é pequena. Portanto, a característica dominante de uma sessão é a personalidade desconhecida e não o que o analisando ou o analista pensam que sabem. Todo progresso sobre 
o conhecimento de si mesmo denota a necessidade de mais investigação. Há uma coisa-em-si que nunca é sabida.

Concluí-se este item refletindo que Bion partiu do princípio de que, sendo a realidade psíquica de natureza diferente, igualmente o procedimento analítico deve ter características próprias. A compreensão de análise é a de um devir constante, entendendo-a como um processo onde analista e analisando se interagem e o desconhecido apresenta-se como a principal referência. Esse caráter dinâmico traz não só consequências metodológicas como também muda o centro de referência para o que os analistas denominam o desenvolvimento da análise. Esse centro é o vir-a-ser de cada sessão, não apenas as interpretações do analista; as intuições da realidade intrapsíquica, não somente os dados sensoriais; as experiências emocionais resultantes de sínteses e comparações e não só as teorias mal relembradas. Se a atitude mental sem memória e sem desejo afasta os protagonistas da análise da realidade sensorial, traz, em contrapartida, a aproximação à verdade última, segundo a linguagem bioniana.

A assim denominada, neste texto, aproximação de Bion à fenomenologia, suspendendo história e futuro do analisando, preserva a identidade do sujeito (analista) e do sujeito (analisando). A análise pessoal recomendada, ao desenvolver a capacidade de discriminar sua realidade intrapsíquica da realidade externa, torna-o capaz de intuir o que não está explícito, apresentando, com maior força e convicção, interpretações baseadas em experiências emocionais e não em teorias mal recordadas. Ele então discrimina, acolhe o sofrimento, entende seu funcionamento, aproxima-se, mas sem que haja um estado confusional. Observa-se que aí Bion se antecipava ao que hoje é tema de pensadores de várias áreas: a intersubjetividade.

\section{Pensando a educação}

O enfoque psicanalítico de Bion permite que o paciente seja o centro da relação analista/analisando. Torna-se fundamental a transformação do papel ativo do primeiro para que o segundo construa e desenvolva sua trajetória de libertação psicoemotiva. Nesse sentido, há uma epoché do analista, para que o analisando se redescubra e assuma as rédeas de sua própria existência.

$\mathrm{Na}$ educação, não faltam iniciativas pedagógicas que reduzem o ensino a favor da aprendizagem. Para Jean-Jacques Rousseau, John Dewey e Jean Piaget, salvo suas diferenças conceituais, o processo pedagógico deve estar centrado nas necessidades do aprendiz. Desde a 
total independência social de Emílio, ao processo de investigação individual, efetuado pelo aluno, que é um sujeito que descobre por si mesmo e ainda à criança que tem seu ritmo e agenda interna de desenvolvimento, a educação saí do algoritmo do professor e segue em vez o algoritmo do aluno.

Nesse sentido, há uma semelhança, guardada a devida proporção, entre o enfoque do método psicanalítico de Bion e a visão de educação moderna, caudatária do pensamento de Jean-Jacques Rousseau, John Dewey e Jean Piaget, no qual se prioriza a carência do aluno.

Ressalte-se, ainda, que para Bion, o analista não prepara a sessão, mas se prepara para o encontro analítico, no sentido de suspender memória e desejo. A formação analítica é imprescindível, assim como a formação de um modo geral. Mas ela não é um instrumento de aplicação sobre o analisando, não é um modelo ou uma prescrição a ser utilizada na sessão, porém, é condição para a ação psicanalítica, para a interpretação, para a análise do caso clínico.

A partir daí, pensa-se que se o educador se propõe a ser co-criador de conhecimento, e não mero transmissor de informações, ele deve preparar-se para a aula, e não preparar a aula. Buscar a ciência, a arte, a cultura, os valores, a filosofia, enfim, tudo o que lhe possibilita iniciar o diálogo com os alunos em situação de estar-com, produzindo um novo conhecimento ou propondo um novo olhar sobre um antigo conhecer. Ensinar o que não sabe, portanto, pesquisar, seguindo o pensamento de Roland Barthes (1989, p. 47).

Há, igualmente, um diálogo, citado neste texto, de Bion com Heisenberg (BION, 1992), o qual provoca reflexões sobre os frequentes momentos em que os educadores assumem tantas certezas que até se esquecem de que a coisa mais certa é a incerteza. Do mesmo modo, a relação pedagógica se dá em direção ao desconhecido: professores, construindo saberes com os alunos. Essa seria uma sabedoria docente que muitas vezes é confundida com as informações teóricas, técnicas, necessárias, mas não suficientes para o ofício do mestre

Convidando também ao diálogo Ildeu Coelho (1999), aprende-se com ele que a fenomenologia educa para a insatisfação com as conclusões alcançadas, buscando incessantemente a verdade, com rigor, não dando margem à superficialidade, aos préconceitos. A importância da reflexão está no rigor e radicalidade em que é feita.

Observa-se que educadores, de forma apropriada, costumam apontar a consciência crítica, a capacidade de julgar como o objetivo último a ser alcançado no processo educativo. Considera-se mais importante a modificação no modo de ser do sujeito do que os tipos de conteúdo que venha a apresentar. Mas o grande desejo do educador é descobrir um método 
que lhe permita, ainda que de modo limitado, caminhar com o educando para essa meta proposta. A redução proposta por Husserl pode ser uma nova forma de sistematização, um novo tipo de reflexão. Ou ainda, uma conversão do olhar que chegue à consciência de si mesmo.

$\mathrm{Na}$ ação educativa, sob esse olhar fenomenológico, o educador encontra um problema, pois, como parte do mundo natural, também deve ele próprio ser posto entre parênteses. Isso significa que, do ponto de vista do educador, a realização, o êxito, é tanto maior quanto menos o educado dependa do mestre para decidir a própria vida. A educação deve ser um processo que libere o homem das influências do mundo, do seu eu psicológico e do próprio professor, e não que o leve à submissão, à adaptação. $\mathrm{O}$ que o método da redução pode realizar é não apenas uma simples abstração, mas, sim, alcançar o eidos da vida verdadeiramente concreta.

Á luz dessa afirmação, e das reflexões neste texto, é razoável dizer que o educado não é o que aprende a teorizar, mas o que aprende um modo especial de ver o mundo.

\title{
PHENOMENOLOGY, PSYCHOANALYSIS AND EDUCATIONAL PROCESS: BETWEEN RATIONALITY AND EMOTION
}

\begin{abstract}
In an interdisciplinary perspective, this work intends to fundament the queries about a possible phenomenology in Bion, when he suggests the mental state without memory or desire towards availability of the analyst to experience the emotional experience that presents itself in the analytic relationship. Starting from hermeneutics readings of some categories found in Husserl and some basic concepts identified in an article "Notes on memory and desire" by Bion, there is an attempt at understanding how the not confusioned state between the annalist and the analyzed person is preserved when using the Bionian procedure. Faithful to the reflection that the studies brought about, the inferences related to the educational process are also presented.
\end{abstract}

Keywords: phenomenology and psychoanalytic, educational process, interdisciplinarity.

\section{LA FENOMENOLOGÍA, EL PSICOANÁLISIS Y EL PROCESO EDUCATIVO: ENTRE LA RACIONALIDAD Y LA EMOCIÓN}

\section{Resumen}

En una perspectiva interdisciplinaria, este trabajo tiene como objetivo apoyar las investigaciones sobre un posible acercamiento a la fenomenología, cuando Bion propone el estado mental sin memoria y sin deseo, en el sentido de la disponibilidad del analista para vivir la experiencia emocional que se presenta en la relación analítica. De una lectura hermenéutica de los conceptos de la epoché fenomenológica de Husserl y de las ideas identificadas en el artículo "Notas sobre la memoria y el deseo" de Bion (1967), se buscó entender cómo se conserva el estado no confusional entre analista y paciente cuando se utiliza 
el procedimento bioniano. En fidelidad a las reflexiones que llevaron a estos estudios, también se presentan las inferencias hechas al proceso educativo.

Palabras clave: Fenomenología y psicoanálisis, proceso educativo, interdisciplinariedad.

\section{Referências}

ABREU-BERNARDES, S. T. (2011). Arte e filosofia na professoralidade. Curitiba, CRV.

ASSIS, M. B. A. C. de. Voilà mon coeur: o gesto amoroso do analista. Ide, São Paulo, v. 34, n. 52, 193-205, 2011. Disponível em: http://www.scielo.br Acesso em 22 abr. 2012.

BACHELARD, G. L'eau et lês rêves: essai sur l'imagination de la matière. Paris: Librairie José Corti, 1942.

BARTHES, R. Leçon: texte de la leçon inaugurale au Collège de France, le 7 janvier 1977. Paris: Seuil Parution, 1989.

BION, W. R. Notes on memory and desire. Psychoanalytic Forum, 2 (3), 271-280, 1967.

Attention and interpretation. London: Karnac, 1984.

Learning from experience. London: Maresfield Library, 1991.

Conversando com Bion: quatro discussões com W.R. Bion; Bion em Nova Iorque e em São Paulo. Tradução de P. C. Sandler. Rio de Janeiro: Imago, 1992.

Editorial, 1995.

Seminarios Clinicos y quatro textos - 1975 hasta 1979. Buenos Aires: Lugar

COELHO, I. M. Fenomenologia e educação. In: BICUDO, M. A. V. e CAPPELLETTI I. F. (Orgs.) Fenomenologia: uma visão abrangente da educação (pp. 53-104). São Paulo: Olho d'Água, 1999. p. 53-104.

DARTIGUES, A. Qu'est-ce que la phénoménologie? Toulouse: Privat 1972.

HUSSERL, E. Ideas relativas a una fenomenologia pura y una filosofia fenomenológica. Tradução de J. Gaos. México: Fondo de Cultura Económica, 1949.

. Conferências de Paris. Tradução de M. J. J. G. de Almeida. 3.ed. São Paulo: Moraes, 
INGARDEN, R. A obra de arte literária. 3.ed. Lisboa: Calouste Gulbenkian, 1965.

JUNQUEIRA-MATTOS, J. A. A tentação de anotar como equivalente ao uso de memória durante a sessão analítica. Alter, Jornal de Estudos Psicodinâmicos, Brasília, n. 7, p. 22-39, 1977.

KELSEN, H. Teoria pura do direito. Tradução de J. B. Machado. 6.ed. São Paulo: Martins Fontes 1998.

LEÃO, E. C. 1977. Aprendendo a pensar. 3.ed. Petrópolis: Vozes, 1977.

MARONI, A. Jung e Bion: aproximações, distanciamentos e desencontros. Cadernos de pesquisa interdisciplinar em Ciências Humanas, v. 6, n. 69, p. 1- 15, 2005. Disponível em: http://www.periodicos.ufsc.br/index.php/cadernosdepesquisa/article/view/1787/4451 Acesso em 19 out., 2012.

RICOEUR, P. Hermenêutica e ideologias. Petrópolis: Vozes, 2008.

ROSA, J. G. Magma. Rio de Janeiro: Nova Fronteira, 1997.

SALLES, W. Paul Ricouer e a hermenêutica de si no espelho das palavras. Utopia y Praxis Latinoamericana, v. 14, n. 47, p. 41-58, 2009. Disponível em: http://www.scielo.org.ve/scielo.php?pid=S1315-52162009000400004\&script=sci_arttext Acesso em 28 jan. 2014, http://www.scielo.br

SARTRE, J.-P. L'être et le néant: essai d'ontologie phénoménologique. Paris: Gallimard, 1943.

Data de recebimento: $29 / 11 / 14$

Data de aceite: $28 / 07 / 16$

\section{Sobre os autores:}

Sueli Teresinha Abreu-Bernardes é Doutora em Educação, membro do Círculo Latinoamericano de Fenomenología - CLAFEN; da Rede de Pesquisadores sobre Professores do Centro-Oeste - REDECENTRO e do Observatorio Internacional de la Profesión Docente OBIPD, da Universitat de Barcelona; coordenadora institucional do Observatório da Educação Interdisciplinaridade na educação básica e do Núcleo de Estudos sobre o Professor, a Arte e a Filosofia-NEPAFi - SE\&PQ/UNIUBE. Professora no Programa de Pós-Graduação em Educação da Universidade de Uberaba. Endereço eletrônico: abreubernardes@terra.com.br

Osvaldo Freitas de Jesus é Doutor em Educação, líder de dois grupos de pesquisa CNPq: o primeiro, interdisciplinar, com foco na Teoria Crítica e o Ensino Superior no Brasil; o 
segundo, no impacto das TICs na antropologia e na educação; membro do OBEDUC PROLER UNIUBE. Endereço eletrônico: freitasdejesus.osvaldo@gmail.com 